\title{
Phosphorylation of Cytadherence-Accessory Proteins in Mycoplasma pneumoniae
}

\author{
LAURIE BARSH DIRKSEN, KATHLEEN A. KREBES, AND DUNCAN C. KRAUSE* \\ Department of Microbiology, University of Georgia, Athens, Georgia 30602
}

Received 1 July 1994/Accepted 7 October 1994

\begin{abstract}
Attachment to host cells of the respiratory epithelium by Mycoplasma pneumoniae is a complex, multicomponent process, requiring a number of accessory proteins in addition to adhesins directly involved in receptor binding. In this study, protein phosphorylation of the cytadherence-accessory proteins HMW1, HMW2, and HMW4 of $M$. pneumoniae was examined using biochemical and immunological techniques. The initial indication of protein modification came from Western immunoblot analysis of the two-dimensional polyacrylamide gel electrophoresis (PAGE) profile of $M$. pneumoniae proteins, revealing multiple spots for both HMW1 and HMW4 that varied in pI but not in size. $M$. pneumoniae cultured in the presence of $\mathrm{H}_{3}{ }^{32} \mathrm{PO}_{4}$ exhibited numerous phosphorylated proteins as detected by sodium dodecyl sulfate-PAGE and autoradiography. These included proteins corresponding to HMW1, HMW2, and HMW4 in electrophoretic mobility. The Triton X-100 partitioning characteristics of these phosphorylated proteins was identical to that described previously for HMW1, -2, and -4. Furthermore, these protein bands were absent when a noncytadhering variant deficient in HMW1-5 was examined in the same manner. Finally, the availability of antiserum to HMW1 and -4 enabled us to confirm by radioimmunoprecipitation that HMW1 and HMW4 are phosphoproteins. Phosphoamino acid analysis of acid-hydrolyzed HMW1 and HMW2 identified primarily phosphothreonine and, to a lesser extent, phosphoserine in HMW1 and predominantly phosphoserine, with a trace of phosphothreonine, in HMW2. Neither protein contained phosphotyrosine. HMW1-HMW5 are components of a cytoskeleton-like structure in $M$. pneumoniae that is thought to function in cell division, changes in cell morphology, gliding motility, and the localization of adhesins in the mycoplasma membrane. Phosphorylation may regulate cytoskeleton dynamics involving these cytadherence-accessory proteins.
\end{abstract}

Protein phosphorylation is a widespread mechanism for regulating intracellular signaling. Through the actions of kinases, phosphotransferases, and phosphatases, this posttranslational protein modification results in various reversible phosphorylation states, modulating cellular events by interconverting between active and inactive protein forms. Control of procaryotic cellular processes by phosphorylation can be grouped into three major classes: phosphoenolpyruvate-dependent phosphotransferase systems, two-component regulatory systems for adaptive responses, and ATP-dependent protein kinases that phosphorylate serine, threonine, and tyrosine residues $(39,40)$. Protein modification by phosphorylation has been established as a regulatory mechanism in eucaryotes since the 1950's (reviewed in references 12, 20, and 33) but has only been described for procaryotic systems in the last decade (9) and very recently in the cell wall-less procaryotes (mycoplasmas) $(35-37,41)$.

The focus of this study is the phosphorylation of specific cytadherence-accessory proteins in Mycoplasma pneumoniae. This species is a pathogen of the human respiratory tract, causing tracheobronchitis and pneumonia, primarily in older children and young adults $(6,10,13)$. Adherence is a pivotal step in $M$. pneumoniae colonization of the respiratory epithelium $(29,42)$ and is accomplished via a specialized tip organelle $(4,7)$ involving two likely adhesin proteins (P1 and P30; 2, 3, 19) as well as several accessory components $(17,26)$. These include the high-molecular-weight, phase-variable proteins HMW1-5 $(25,26,43)$, some or all of which are thought to be

* Corresponding author. Phone: (706) 542-2671. Fax: (706) 5422674. Electronic mail address: DKRAUSE@UGA.CC.UGA.EDU. required for the anchoring of the adhesin protein $\mathrm{P} 1$ to the attachment organelle $(1,45)$.

Treatment of $M$. pneumoniae cells with the nonionic detergent Triton X-100 solubilizes the mycoplasma membrane, revealing a filamentous, cytoskeleton-like network of proteins (Triton shell; 14, 22, 31). The HMW proteins partition with the Triton X-100-insoluble fraction, consistent with a scaffolding role in cytadherence (44). Furthermore, immunoelectron microscopy studies demonstrate that HMW1 and HMW4 have a distinct subcellular distribution, localizing exclusively to the filamentous extensions of the mycoplasma cell (44). On the basis of peptide mapping and immunoblot analysis, the chemical and antigenic properties of these proteins are almost identical (44). Both are associated with the mycoplasma membrane (11) and appear to have intracellular and extracellular domains $(11,44)$. We report here that HMW1 and HMW4 are phosphorylated and characterize the nature of that modification. In addition, we present evidence indicating that HMW2 may also be phosphorylated.

\section{MATERIALS AND METHODS}

Organisms and culture conditions. Wild-type virulent $M$. pneumoniae M129 B18 and a spontaneously arising, cytadherence-negative variant of M129 which lacks proteins HMW1-5 (class I, variant no. 2 [26]) were used in these studies. The cells were grown in $75-\mathrm{cm}^{2}$ tissue culture flasks containing $25 \mathrm{ml}$ of Hayflick medium (18) at $37^{\circ} \mathrm{C}$ and harvested during exponential growth, when the phenol red $\mathrm{pH}$ indicator became orange (after approximately $65 \mathrm{~h}$ of incubation). Wild-type cultures, which adhere well to plastic, were washed three times with Tris-saline (TS; $0.15 \mathrm{M} \mathrm{NaCl}-20 \mathrm{mM}$ Tris-HCl [pH 7.5]), scraped into TS, and centrifuged at $30,000 \times g$ for $30 \mathrm{~min}$. The 
class I variant attaches poorly to plastic and therefore was harvested and washed by centrifugation.

Analysis of $M$. pneumoniae proteins labeled with ${ }^{32} \mathbf{P}_{i}$ during culture. The Hayflick medium was removed from wild-type mycoplasma cultures in the log phase of growth, and after three washes with $\mathrm{TS}$ at $37^{\circ} \mathrm{C}$ it was replaced with $10 \mathrm{ml}$ of phosphate-free culture medium (Dulbecco's Modified Eagle's Medium [Sigma Chemical Co., St. Louis, Mo.] supplemented with nonessential amino acids [Sigma Chemical Co.], $20 \mathrm{mM}$ HEPES [ $N$-2-hydroxyethyl piperazine- $N-2^{\prime}$ ethanesulfonic acid, $\mathrm{pH} 7.4]$ ), containing $10 \%$ horse serum dialyzed against TS. The nonadhering mycoplasma variant was harvested by centrifugation as described above, and the resulting pellet was suspended in $10 \mathrm{ml}$ of phosphate-free culture medium-10\% dialyzed horse serum and transferred to a new $75-\mathrm{cm}^{2}$ tissue culture flask for labeling. $\mathrm{H}_{3}{ }^{32} \mathrm{PO}_{4}$ (Dupont NEN Research Products, Boston, Mass.; 8,500 to $9,120 \mathrm{Ci} / \mathrm{mmol}$ ) was added to a final concentration of 30 $\mu \mathrm{Ci} / \mathrm{ml}$, and the incubation was continued for an additional $15 \mathrm{~min}$ to $6 \mathrm{~h}$ (generally $2 \mathrm{~h}$ unless otherwise indicated) at $37^{\circ} \mathrm{C}$, after which the cells were harvested and washed with TS by centrifugation.

Triton X-100 fractionation and sodium dodecyl sulfatepolyacrylamide gel electrophoresis (SDS-PAGE). Mycoplasmas were extracted with Triton X-100 as described elsewhere (44), but the method was modified by the addition of DNase and RNase at $50 \mu \mathrm{g} / \mathrm{ml}$ each. The samples were subjected to SDS-PAGE (27) with acrylamide concentrations of 3 and $4.5 \%$ in the stacking and separating gels, respectively. In some cases, electrophoresis was continued until the dye front and lowmolecular-weight forms of ${ }^{32} \mathrm{P}$ had migrated from the bottom of the gels in order to reduce background levels in autoradiographs. Gels were either stained with $0.25 \%$ Coomassie brilliant blue in $10 \%$ glacial acetic acid $-45 \%$ methanol and destained in $8.3 \%$ glacial acetic acid-25\% methanol or processed for electrophoretic transfer to polyvinylidene difluoride membranes (PVDF; Bio-Rad Laboratories, Hercules, Calif.) according to the method of Towbin et al. (46), with the exception that methanol was omitted from the transfer buffer. Dried gels or PVDF membranes were exposed to Kodak XAR film (Rochester, N.Y.) at $-80^{\circ} \mathrm{C}$ in the presence of an intensifier screen. Exposure times ranged from 1 to 14 days, depending on the application.

Two-dimensional (2-D) gel electrophoresis and Western (immunoblot) analysis. Wild-type mycoplasmas were fractionated with Triton X-100, and the Triton X-100-insoluble fraction was subjected to 2-D PAGE according to the method of O'Farrell (34) with modifications $(17,26)$. Separation was by isoelectric focusing and SDS-PAGE in the first and second dimensions, respectively. Proteins were then blotted to nitrocellulose (Micron Separations Inc., Westboro, Mass.; 46) and probed with specific antiserum against HMW1/HMW4 that was prepared and characterized as described previously (25, 44).

Radioimmunoprecipitation. ${ }^{32} \mathrm{P}_{\mathrm{i}}$-labeled mycoplasma cell pellets were suspended in $500 \mu$ l TDST (1\% Triton X-100, $0.2 \%$ sodium deoxycholate, $0.1 \%$ SDS, $10 \mathrm{mM}$ Tris $\mathrm{HCl}[\mathrm{pH}$ 7.8]) containing $1 \mathrm{mM}$ phenyl methylsulfonyl fluoride and 50 $\mu \mathrm{g}$ each of DNase and RNase per $\mathrm{ml}$ and incubated at $37^{\circ} \mathrm{C}$ for $30 \mathrm{~min}$. An equal volume of TDST containing $20 \mathrm{mM}$ EDTA (pH 7.8) was added, and the incubation was continued for an additional $30 \mathrm{~min}$. The preparation was centrifuged at 55,000 rpm for 30 min using a Beckman Optima TL Ultracentrifuge and TLA 100.3 rotor (Palo Alto, Calif.) to remove insoluble material. In previous studies with ${ }^{35} \mathrm{~S}$-methionine-labeled $M$. pneumoniae (28), this combination of detergents resulted in solubilization of $>95 \%$ of the radioactivity. The supernatant, containing detergent-soluble antigen, was collected and combined with either preimmune serum or HMW1/HMW4-specific antiserum $(250-\mu \mathrm{l}$ aliquot of soluble antigen plus $50 \mu \mathrm{l}$ of serum) and incubated overnight at $4^{\circ} \mathrm{C}$ on a rocker platform. Protein A-bearing Staphylococcus aureus cells (Cowan 1 strain), prepared according to the method of Kessler (24), were washed twice with TDSET (TDST plus 10 mM EDTA, pH 7.8) and suspended in TDSET to a final concentration of $10 \%$. This was added to the antibody-antigen mixture $(100 \mu l$ per sample), and the mixture was incubated for $2 \mathrm{~h}$ at $4^{\circ} \mathrm{C}$ on a rocker platform. The $S$. aureus cells were washed six times with TDSET by centrifugation to remove nonimmunologically bound antigen and suspended in $0.1 \mathrm{M}$ Tris $\mathrm{HCl}-2 \% \mathrm{SDS}-$ $20 \%$ glycerol (vol/vol) $-4 \%$ (wt/vol) $\beta$-mercaptoethanol- $-0.02 \%$ bromphenol blue ( $\mathrm{pH}$ 6.8). The samples were boiled for $5 \mathrm{~min}$ and centrifuged to remove the $S$. aureus cells. The resulting supernatants were collected and analyzed by SDS-PAGE and autoradiography as described above.

Phosphoamino acid analysis (PAA). ${ }^{32} \mathbf{P}_{\mathrm{i}}$-labeled mycoplasma preparations were fractionated with Triton $X-100$, and detergent-insoluble proteins were separated by SDS-PAGE and transferred electrophoretically to PVDF membranes as described above. Protein bands were visualized by India ink staining (16). Briefly, the blot was washed twice in $0.4 \%$ Tween 20 in Tris-buffered saline (TBS) $(0.5 \mathrm{M} \mathrm{NaCl}-20 \mathrm{mM}$ Tris- $\mathrm{HCl}$, $\mathrm{pH} \mathrm{7.5)} \mathrm{for} 5 \mathrm{~min}$, stained for $1.5 \mathrm{~h}$ in TBS containing $1 \mu \mathrm{l}$ of India ink per $\mathrm{ml}-0.3 \%$ Tween 20 , and destained in TBS. HMW1 and HMW2 were identified on the basis of their characteristic migration and confirmed by comparison with the profile of an HMW1-HMW5-deficient variant. Alternatively, labeled protein bands were located by incubating unstained blots under film for 24 to $48 \mathrm{~h}$ at $-80^{\circ} \mathrm{C}$ by using an intensifier screen. The exposed film was then aligned with the PVDF membrane with the aid of GLOGOS alignment stickers (Stratagene, La Jolla, Calif.), and bands of interest were carefully excised from the PVDF membranes for phosphoamino acid analysis (5). Protein samples were partially hydrolyzed in $6 \mathrm{~N}$ $\mathrm{HCl}$ at $110^{\circ} \mathrm{C}$ for $1 \mathrm{~h}$, dried by vacuum evaporation, and suspended in $10 \mu$ l of $\mathrm{pH} 1.9$ buffer (2.5\% formic acid-7.8\% glacial acetic acid) containing $0.4 \mu \mathrm{g}$ each of phosphoamino acid standards (phosphoserine, phosphothreonine, and phosphotyrosine; Sigma Chemical Co.). Eight-microliter volumes of the samples were spotted onto cellulose thin-layer chromatography plates (CBS Scientific Company, Inc., Del Mar, Calif.) and electrophoresed in the first dimension with $\mathrm{pH} 1.9$ buffer at $1,500 \mathrm{~V}$ for $25 \mathrm{~min}$ and in the second dimension with pH 3.5 buffer (5\% glacial acetic acid, $0.5 \%$ pyridine, $1 \mathrm{mM}$ EDTA) at $1,300 \mathrm{~V}$ for $20 \mathrm{~min}$ (Hunter Thin-Layer Electrophoresis System-7000; CBS Scientific Company, Inc.). Unlabeled phosphoamino acid standards were visualized by ninhydrin staining $(0.25 \%$ [wt/vol] ninhydrin in acetone), while ${ }^{32} \mathrm{P}$-labeled phosphoamino acids were detected by autoradiography at $-80^{\circ} \mathrm{C}$ in the presence of an intensifier screen.

\section{RESULTS}

2-D analysis of HMW1 and HMW4. The initial indication that proteins HMW1 and HMW4 might undergo modification came from Western blot analyses of $M$. pneumoniae protein profiles following 2-D PAGE (Fig. 1). HMW1 and HMW4 $\left(M_{\mathrm{r}}\right.$ 210,000 and 215,000 , respectively), which have been shown to be structurally and antigenically very similar (44), yielded multiple spots that varied in pI but not in $M_{\mathrm{r}}$ when visualized immunologically using HMW1/HMW4-specific antiserum. Such a pattern can result from various degrees of protein 


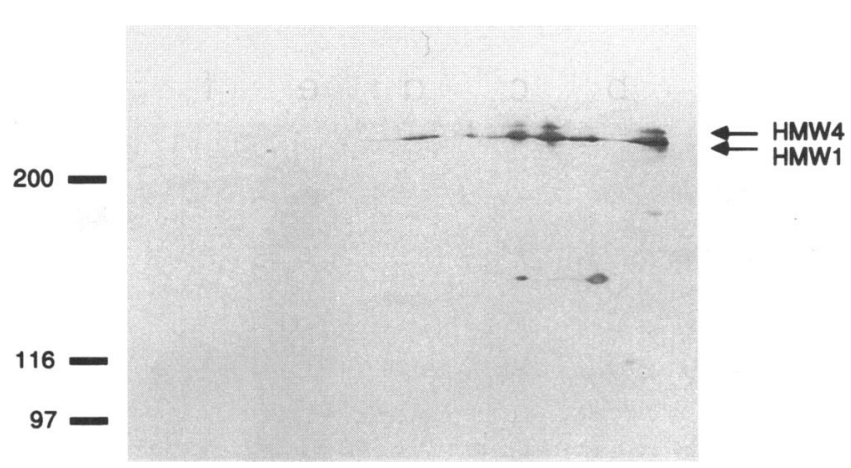

FIG. 1. Western blot analysis of a 2-D PAGE profile of $M$. pneumoniae proteins using HMW1/HMW4-specific antiserum. Mycoplasma proteins were separated in the first dimension by $\mathrm{pI}$ and in the second dimension by size, electroblotted to nitrocellulose, and probed with HMW1/HMW4-specific antiserum (44) at a dilution of 1:100. The profile is shown according to convention (34), with the acidic end to the right. HMW1 and HMW4 and protein standards (in kilodaltons) are indicated in the margins.

phosphorylation, with the addition of each phosphate group making the protein more acidic $(8,30)$. Six spots were observed for HMW1, raising the possibility that this protein is phosphorylated at more than one site. Analysis of protein profiles of parallel samples by silver staining demonstrated that multiple spotting of proteins was not a generalized phenomenon (data not shown) and therefore probably is not an artifact of sample preparation, as can occur by carbamylation, for example, if samples are heated in the presence of urea prior to 2-D PAGE.

Incorporation of ${ }^{32} \mathrm{P}_{\mathrm{i}}$ into mycoplasma proteins during culture. In order to examine protein phosphorylation directly, we analyzed $M$. pneumoniae protein profiles by SDS-PAGE following culture for 15 to $120 \mathrm{~min}$ in the presence of ${ }^{32} \mathrm{P}_{\mathrm{i}}$. A low acrylamide concentration was used to optimize separation of higher-molecular-weight proteins. Autoradiography revealed numerous phosphorylated proteins, with band intensity dependent upon labeling time (Fig. 2).

When SDS-PAGE profiles of ${ }^{32} \mathrm{P}_{\mathrm{i}}$-labeled $M$. pneumoniae proteins were treated with $0.1 \mathrm{~N} \mathrm{NaOH}$ in $50 \%$ methanol for $1 \mathrm{~h}$ at room temperature with gentle shaking prior to autoradiography, no changes were observed compared to untreated gel profiles (data not shown). This treatment reportedly removes noncovalently associated phosphate-containing moieties such as ATP, phosphoenol pyruvate and $\mathrm{P}_{\mathrm{i}}$ from proteins (38). The resistance to mild methanol- $\mathrm{NaOH}$ suggests that the radioactive bands visualized in autoradiographs were due to phosphorylation by covalent modification(s).

Autoradiographs consistently revealed bands corresponding in relative mobility to HMW proteins, although in some experiments (e.g., Fig. 2), HMW4 was not resolvable from HMW1. In order to evaluate further the identity of these bands, the profile of phosphorylated proteins from wild-type $M$. pneumoniae was compared to that of the noncytadhering variant lacking HMW1-HMW5 (Fig. 3B, lanes a and b, respectively). Bands corresponding to HMW1, -2 , and -4 in the wild-type profile were absent or greatly reduced in the profile of the variant lacking HMW1-HMW5. It is noteworthy that we also observed radioactive bands corresponding to HMW3 and $\mathrm{P} 1$ in relative mobility in some experiments (Fig. 3B, lane a), and we have confirmed by radioimmunoprecipitation that $\mathrm{P} 1$ is a phosphoprotein (data not shown). However, for reasons not yet clear to us, the phosphorylation of these proteins was variable, and further analysis is beyond the scope of this study.

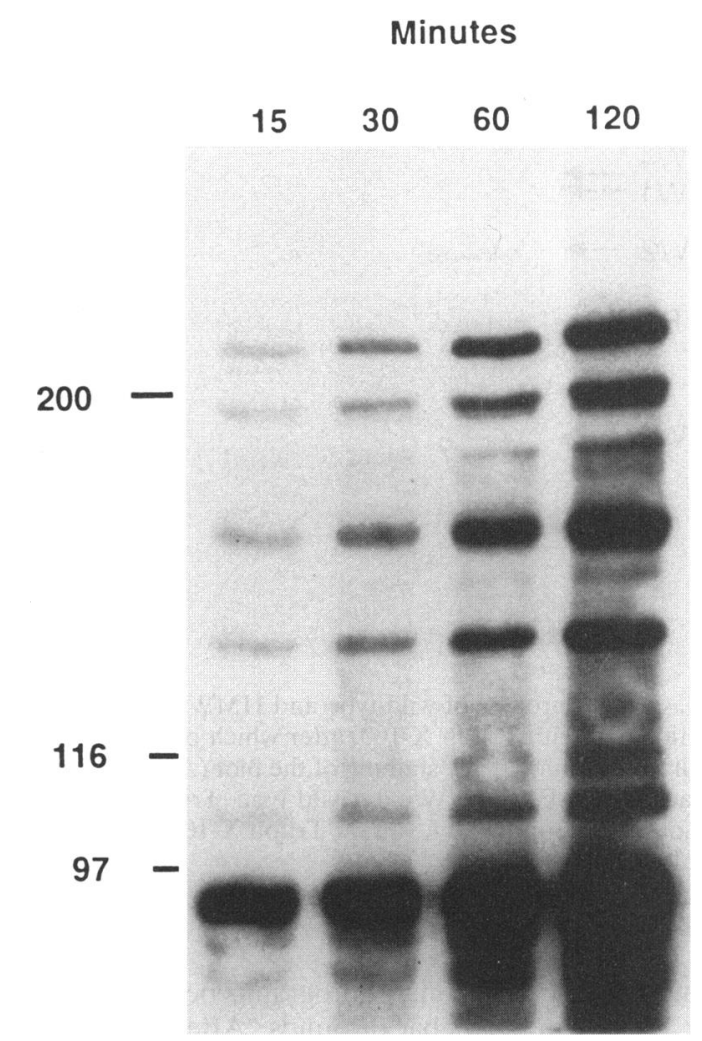

FIG. 2. Protein profile of wild-type $M$. pneumoniae cultured in the presence of $\mathrm{H}_{3}{ }^{32} \mathrm{P}_{\mathrm{i}} \mathrm{O}_{4}$ for increasing lengths of times. Mycoplasmas were metabolically labeled for the indicated times as described in the text. Proteins were separated by SDS-PAGE, electroblotted to a PVDF membrane, and visualized by autoradiography. The position of protein standards is indicated to the left in kilodaltons.

Triton X-100 fractionation. HMW1-HMW5 are components of an interconnected network of Triton X-100-insoluble proteins thought to constitute a cytoskeleton (43-45). When $M$. pneumoniae cells cultured in ${ }^{32} \mathrm{P}_{\mathrm{i}}$ were Triton $\mathrm{X}-100$ fractionated, radioactive bands corresponding to HMW1, HMW2, and HMW4 in relative mobility were substantially enriched in the detergent-insoluble fraction (Fig. 3A and B, lane e), and absent (HMW1 and HMW4) or greatly reduced (HMW2) in the detergent-soluble fraction (Fig. 3A and B, lane c). Profiles of the Triton X-100-soluble and -insoluble fractions from the HMW1-HMW5-deficient variant are shown in lanes $d$ and $f$, respectively, of Fig. $3 \mathrm{~A}$ and $\mathrm{B}$, for comparison. The presence of HMW proteins at reduced levels in the variant Triton X-100insoluble profile is consistent with the reversible nature of this phenotypic switching (25) and the enrichment for these proteins in the Triton shell (44).

Radioimmunoprecipitation analysis. On the basis of electrophoretic mobility and Triton X-100 fractionation patterns of wild-type and variant proteins following metabolic labeling with ${ }^{32} \mathrm{P}_{\mathrm{i}}$, HMW1, HMW2, and HMW4 appear to be phosphorylated. To confirm the identity of the radioactive bands directly, ${ }^{32} \mathrm{P}_{\mathrm{i}}$-labeled $M$. pneumoniae proteins were analyzed by radioimmunoprecipitation. HMW1/HMW4-specific antiserum reproducibly precipitated two radioactive bands corresponding to HMW1 and HMW4 in relative mobility $\left(M_{\mathrm{r}} 210,000\right.$ and 215,000 , respectively), providing direct evidence that HMW1 and HMW4 were phosphorylated (Fig. 4, lane c). The radioactive band corresponding to HMW4 was generally very faint 


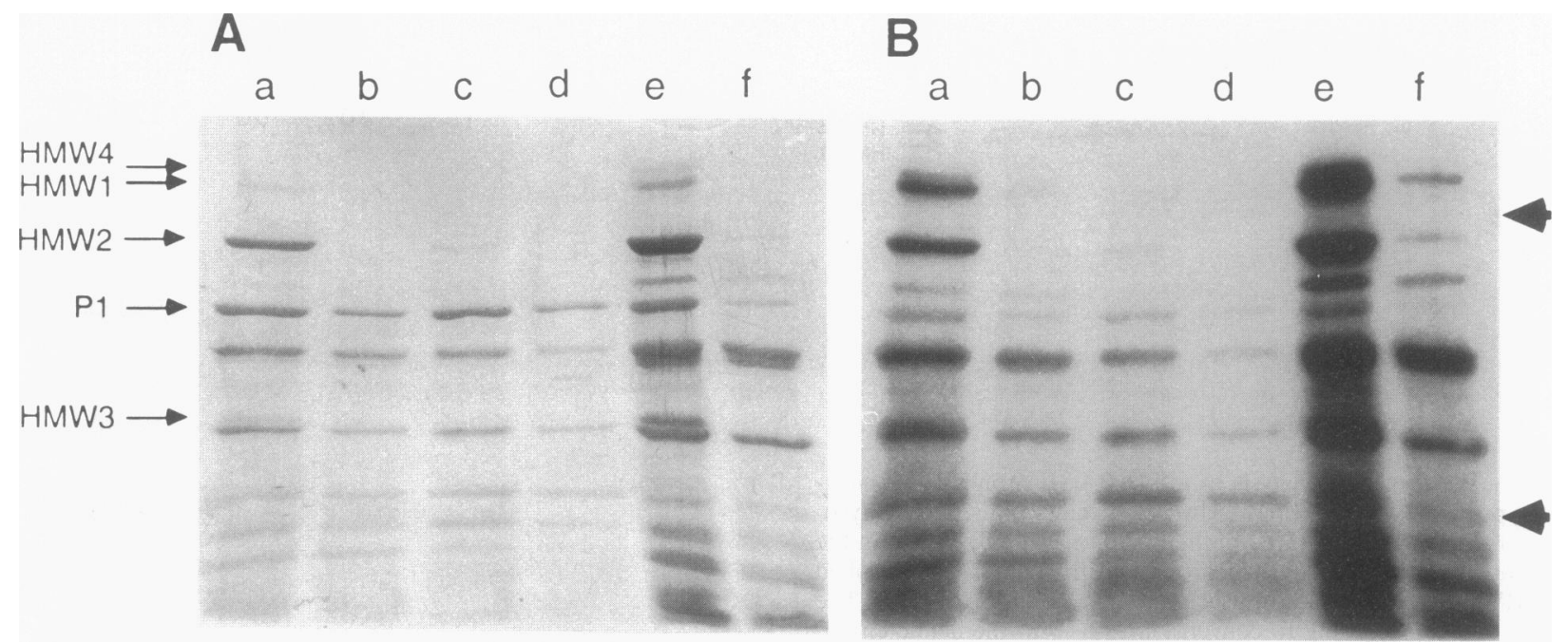

FIG. 3. Protein profiles of wild-type and HMW1-HMW5-deficient variant $M$. pneumoniae cultured in the presence of $\mathrm{H}_{3}{ }^{32} \mathrm{PO}$. Mycoplasmas were fractionated with Triton X-100, after which proteins in each fraction were separated by SDS-PAGE, electroblotted to a PVDF membrane, and visualized by amido black staining of the blot (A) or autoradiography (B). Lanes: a, unfractionated wild-type M. pneumoniae; b, unfractionated variant lacking HMW1-HMW5; c, wild-type Triton X-100-soluble fraction; d, variant Triton X-100-soluble fraction; e, wild-type Triton $\mathrm{X}$-100-insoluble fraction; and f, variant Triton X-100-insoluble fraction. Protein standards are indicated by arrowheads in the right margin: upper, $200 \mathrm{kDa}$; lower, $116 \mathrm{kDa}$.

and did not reproduce well in photographs because of its weak intensity relative to high backgrounds. Attempts to prepare HMW2-specific antiserum have been unsuccessful. Interestingly, however, the paired preimmune and immune sera both reacted with a protein corresponding to HMW2 in size (Fig. 4, lanes $b$ and $c$, respectively).

PAA. Radiolabeling of HMW1, HMW2, and HMW4 was stable in response to $15 \%$ trichloroacetic acid treatment for 15 min at $100^{\circ} \mathrm{C}$ (data not shown), suggesting that the phosphoryl moieties were attached via O-phosphomonoester linkages (phosphoserine, phosphothreonine, and/or phosphotyrosine). PAA was performed to establish the identity of phosphorylated amino acids. Proteins labeled with ${ }^{32} P_{i}$ during culture were purified by SDS-PAGE, acid hydrolyzed, and subjected to 2-D thin-layer electrophoresis to resolve phosphoserine, phosphothreonine, and phosphotyrosine. Radioactive amino acids were visualized by autoradiography and then identified based upon comigration with phosphoamino acid standards. As shown in Fig. 5A, the majority of the ${ }^{32} \mathrm{P}_{\mathrm{i}}$ label in HMW1 was associated with phosphothreonine, with low levels of phosphoserine also being detectable. The reverse was true for HMW2, where phosphoserine was the predominant phosphoamino acid, with phosphothreonine also being detectable (Fig. 5B). No phosphotyrosine was observed in HMW1 or HMW2. HMW4 was not available in sufficient quantities to permit PAA at this time.

Serum requirement. PAA identified phosphoserine and phosphothreonine in HMW1 and HMW2, suggesting that phosphorylation may result from the activity of a serine/ threonine-specific kinase(s). To determine if phosphorylation required the presence of the dialyzed serum, which could contain exogenous kinase activity, phosphorylation profiles generated in the presence or absence of serum were compared (Fig. 6). The autoradiograph was purposely underexposed in the control profile (Fig. 6, lane a) to allow resolution of the bands in lanes $b$ and c. Interestingly, when serum was absent during the preincubation only (Fig. 6, lane b) or during both the preincubation and labeling (Fig. 6, lane c), phosphorylation was actually enhanced. Thus, serum is not required for phos- phorylation, which appears to be the result of mycoplasma function. Furthermore, the unexpected enhancement when serum was omitted raises the possibility that the presence or absence of serum factor(s) might modulate kinase and/or phosphatase activities.

\section{DISCUSSION}

The phase-variable proteins HMW1-HMW5 are thought to play an important though indirect role in the colonization of the respiratory epithelium by $M$. pneumoniae. Phase variants lacking these accessory proteins are unable to cytadhere and fail to cluster the adhesin protein $\mathrm{P} 1$ at the attachment organelle (1) which has an altered appearance in the variants due to the loss of the spherical tip to the electron-dense core $(1,45)$. On the basis of these observations, the HMW proteins are thought to have a scaffolding function, with responsibilities that include the localization and anchoring of adhesin proteins to the attachment organelle as well as maintenance of the correct architecture of the tip structure. How these proteins accomplish this task is not understood. The studies described here reveal the covalent phosphorylation of certain HMW proteins, a process capable of regulating protein function.

Western blot analysis of 2-D PAGE profiles of $M$. pneumoniae proteins using HMW1/HMW4-specific antiserum provided an initial indication that HMW1 and HMW4 might undergo modification by phosphorylation. The presence of multiple isoforms for HMW1 and HMW4 is suggestive of phosphorylation at more than one site and is consistent with the detection of both phosphoserine and phosphothreonine in HMW1. The culture of $M$. pneumoniae cells in the presence of ${ }^{32} \mathrm{P}_{\mathrm{i}}$ resulted in the incorporation of radioactive label into HMW1 and HMW4 and suggested that HMW2 may likewise be phosphorylated. We attempted to analyze proteins from mycoplasma cells cultured with ${ }^{32} \mathbf{P}_{i}$ by $2-D$ PAGE in order to correlate the pattern observed for HMW1 and HMW4 by Western blot analysis with the extent of phosphorylation and to determine if these proteins were also present in a nonphos- 


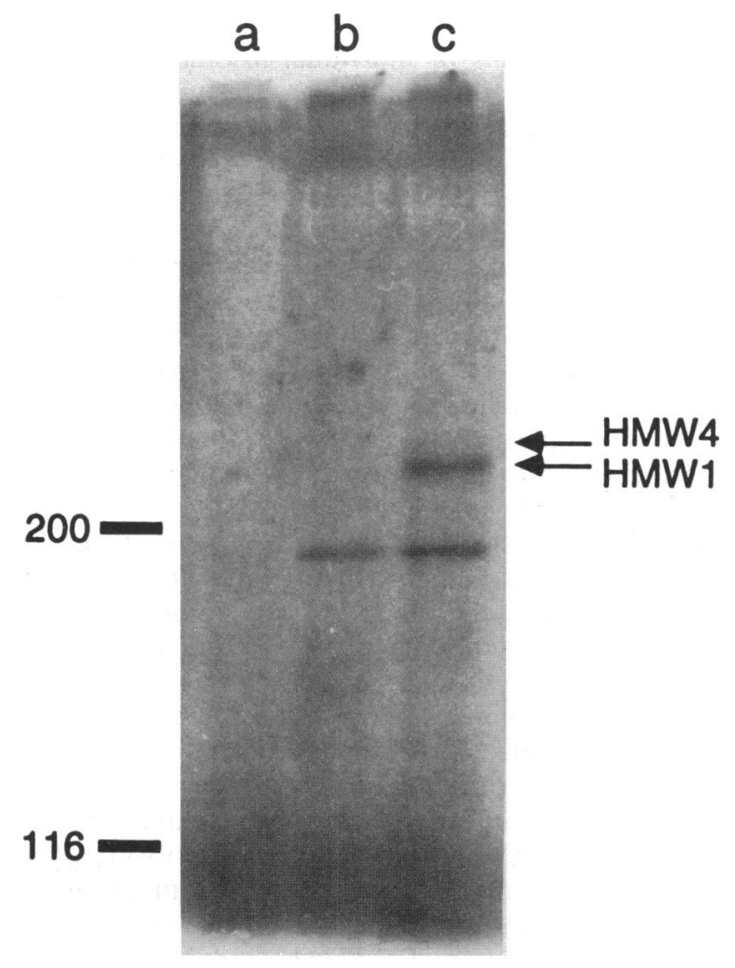

FIG. 4. Radioimmunoprecipitation of $M$. pneumoniae proteins cultured in $\mathrm{H}_{3}{ }^{32} \mathrm{PO}_{4}$ using HMW1/HMW4-specific antiserum. Lanes: a, precipitation using serum-free control; $b$, precipitation using preimmune serum; c, precipitation using HMW1/HMW4-specific antiserum. Protein standards are indicated in kilodaltons.

phorylated state (data not shown). These attempts were complicated by high levels of background radioactivity in 2-D gels as well as by limitations in sensitivity compared to immunoblot analysis. A 1-D isoelectric focusing approach for analyzing the phosphorylation state of proteins has been described $(8,30)$ which might be useful for future studies.

Preliminary experiments for radiolabeling mycoplasmas with ${ }^{32} \mathrm{P}_{\mathrm{i}}$ during culture employed phosphate-depleted Hayflick medium and yielded phosphorylation profiles comparable to those shown in Fig. 3 but requiring much longer times for both culture and exposure of autoradiographs. The change to a phosphate-free minimal medium with dialyzed serum greatly reduced competing nonradioactive phosphate, thereby decreasing culture times from $24 \mathrm{~h}$ to as little as $15 \mathrm{~min}$ and autoradiograph exposure times from 14 days to 1 to 2 days, while resulting in no detectable changes in mycoplasma total protein profiles (data not shown). This phosphorylation protocol should allow studies into possible environmental or growth stage-related influences on the phosphorylation state of mycoplasma proteins, where narrow windows for ${ }^{32} \mathrm{P}_{\mathrm{i}}$ pulselabeling are required. The latter might account for the variability noted in the phosphorylation of HMW3, HMW4, and P1. Nevertheless, the possible physiological consequences of culture under conditions of limiting phosphate should be taken into consideration. Preliminary studies omitting the preincubation in phosphate-free medium indicate that this step is not necessary, as phosphoprotein patterns appeared to be identical to those seen in Fig. 2 and 3. Finally, serum is not required for phosphorylation, which appears to be the result of mycoplasma function.

The partitioning characteristics of the phosphorylated high-
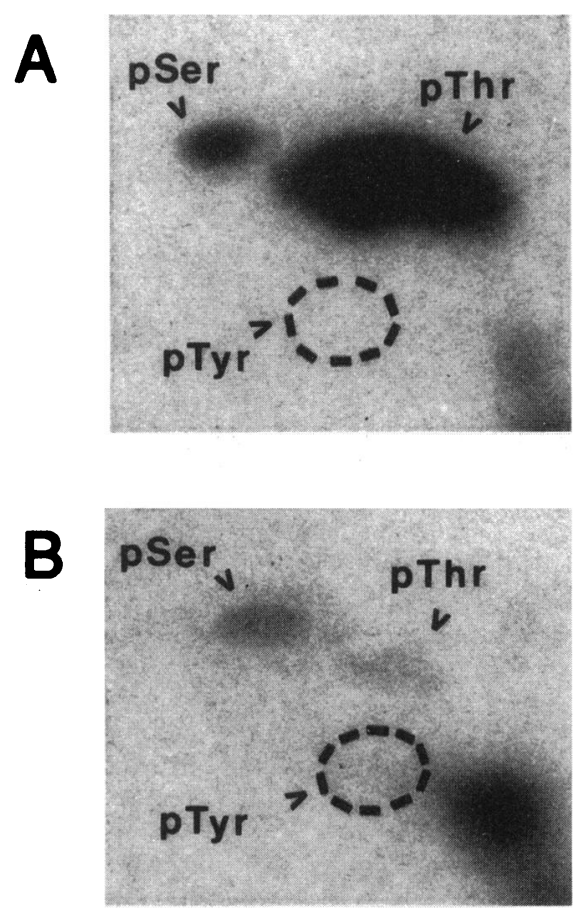

FIG. 5. Phosphoamino acid analysis by 2-D thin-layer electrophoresis and autoradiography. $M$. pneumoniae proteins were labelled with $\mathrm{H}_{3}{ }^{32} \mathrm{PO}_{4}$ during culture, separated by SDS-PAGE, and electroblotted to PVDF. The bands corresponding to HMW1 and HMW2 were excised, subjected to partial hydrolysis in $6 \mathrm{~N} \mathrm{HCl}$, and analyzed for phosphoamino acid residues (5). Nonradioactive phosphoserine (pSer), phosphothreonine (pThr), and phosphotyrosine (pTyr) standards were included in each sample and visualized by ninhydrin staining. Radioactive phosphoamino acids were visualized by autoradiography, with an exposure length of 2 weeks. A, HMW1; B, HMW2.

molecular-weight proteins following incubation of radiolabeled mycoplasmas with Triton $\mathrm{X}-100$ were consistent with those described for HMW1, HMW2, and HMW4 (44). Specifically, HMW1 and HMW4 are associated exclusively with the Triton X-100-insoluble, cytoskeleton-like fraction, while HMW2 appears to be associated primarily with the detergentinsoluble fraction but is also associated to a small extent with the detergent-soluble fraction. Thus, there is no indication that the extent of phosphorylation affects Triton X-100 partitioning of these proteins.

Analysis of ${ }^{32} \mathrm{P}_{\mathrm{i}}$-labeled $M$. pneumoniae by radioimmunoprecipitation using antiserum specific to HMW1 and HMW4 yielded protein bands in autoradiographs corresponding in size to HMW1 and HMW4, providing direct evidence for their identity. Attempts to generate HMW2-specific antiserum have been unsuccessful; hence, we are unable to confirm by immunologic means the identity of the phosphoprotein corresponding to HMW2 in electrophoretic mobility. However, the absence of this band in the variant deficient in HMW1-HMW5 and its partitioning characteristics in the presence of Triton X-100 are consistent with its identity being HMW2. However, we cannot rule out the possibility of a protein comigrating with HMW2 that requires one or more of the HMW proteins for phosphorylation.

The acid stability of labeling seen in total protein profiles in polyacrylamide gels indicated that many of the phosphoproteins visualized in autoradiographs possessed O-phosphomonoester linkages. Furthermore, phosphoamino acid analysis of 


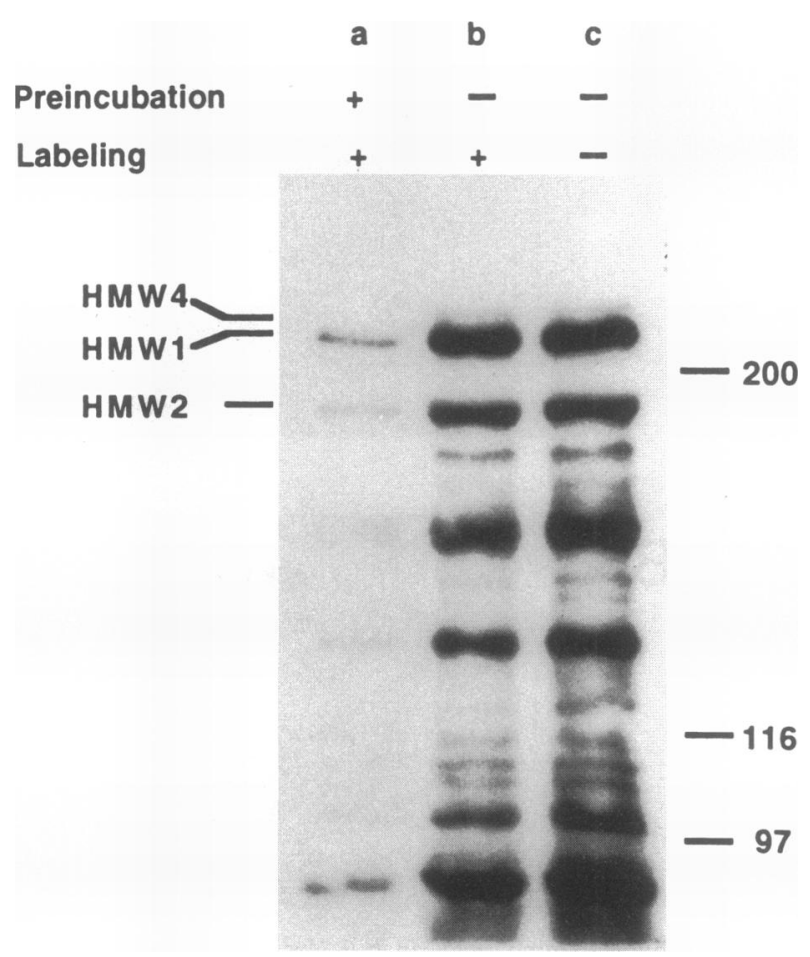

FIG. 6. Electrophoretic profile of $M$. pneumoniae proteins metabolically labeled with $\mathrm{H}_{3}{ }^{32} \mathrm{PO}_{4}$ during culture in the presence or absence of serum. Mycoplasmas in lane a were prepared with a 2-h preincubation in the HEPES-buffered phosphate-free minimal essential medium containing $10 \%$ dialyzed horse serum, followed by a 2-h incubation with ${ }^{32} \mathrm{P}_{\mathrm{i}}$. Serum was omitted only from the preincubation for the cells in lane $b$ and from both the preincubation and labeling for the cells in lane c. + , serum present; - , serum absent. Protein size standards are indicated in the left margin in kilodaltons.

acid-hydrolyzed HMW1 and HMW2 revealed predominantly phosphothreonine and phosphoserine, respectively. These findings indicate that HMW1 and HMW2 are substrates for a mycoplasma serine/threonine kinase. However, they do not preclude the presence of acid-labile linkages, such as phosphoramidates (phosphohistidine, phosphoarginine, and phospholysine) and phosphate anhydrides (phosphoaspartic acid and phosphoglutamic acid) in addition to the phosphoserine and phosphothreonine in HMW1 and HMW2. Precedents exist for the presence of different types of phosphate linkages within a protein $(39,40)$, indicating that two different phosphoregulatory processes may be in effect. The analysis of HMW1, HMW2, and HMW4 for the possible presence of acid-labile phosphate linkages is currently underway.

M. pneumoniae exhibits fundamental cellular processes that, in eucaryotes, have been associated with cytoskeleton function. These include cell migration on solid surfaces (by gliding motility), binary fission, specific changes in cell morphology, and nonrandom localization in the plane of the membrane of specific proteins such as those involved in cell adhesion. Extraction of $M$. pneumoniae cells with the nonionic detergent Triton X-100 reveals an insoluble framework of associated proteins $(14,31)$, which is likewise reminiscent of eucaryotic cytoskeletons. Proteins HMW1-HMW5 partition with the Triton shell and are not easily dissociated from the cytoskeleton fraction by salt extractions (45). Furthermore, when applied to sucrose density gradients, the HMW proteins comigrate with the cytoskeleton (44). These observations suggest that HMW1-
HMW5 interact specifically with the cytoskeleton, as opposed to nonspecific trapping or individual insolubility. Finally, the failure of phase variants lacking these proteins to cluster the adhesin protein P1 at the attachment organelle (35) provides functional evidence of a cytoskeleton association.

Spatial analysis of HMW1 and -4 by immunoelectron microscopy indicates that these proteins localize exclusively along the filamentous extensions of the mycoplasma cell, with little detectable association with the cell body. This subcellular distribution seems particularly noteworthy with respect to basic cellular functions, especially in the context of protein phosphorylation. One might anticipate that significant reconfiguration of the mycoplasma cytoskeleton occurs in this region, as might be necessary to accommodate dynamic processes such as changes in cell morphology, gliding motility, cell division, or localization of adhesins in the mycoplasma membrane. Such reconfigurations could include disassembly and reassembly of cytoskeletal elements as well as disassociation and reassociation with the cell membrane and might be regulated by the phosphorylation state of component proteins.

The phosphorylation state regulates protein function for most phosphoproteins described to date in both procaryotes and eucaryotes. These include common fundamental processes such as nutrient transport, intermediary metabolism, and cellular differentiation. Furthermore, phosphorylation/dephosphorylation events involving cytoskeletal elements in eucaryotic cells are one of several types of factors regulating protein function, where activation of certain kinases in several different cell types is associated with changes in the phosphorylation state of some cytoskeletal proteins as well as changes in cell morphology (32). The possibility that phosphorylation may help regulate cytoskeleton dynamics in $M$. pneumoniae, as suggested by Kahane et al. (21), is intriguing. The gene for HMW1 has been sequenced (11), revealing candidate phosphorylation sites based upon consensus eucaryotic kinase recognition motifs (23). Experiments are currently in progress to identify the location of phosphoamino acids within the primary sequence. Studies in other systems have demonstrated the power of genetic approaches in defining the role of phosphorylation in protein function. Genetic approaches under development for use in M. pneumoniae (15) show promise in eventually clarifying the function of the HMW proteins and the role of phosphorylation therein.

\section{ACKNOWLEDGMENTS}

This work was supported by Public Health Service research grant AI33396 and research career development award AI00968 from the National Institute of Allergy and Infectious Diseases.

We thank Kathy Gould at Vanderbilt University School of Medicine and Jonathan Ladapo and Kyungok $\mathrm{K}$. Lee at the University of Georgia for their advice and technical assistance.

\section{REFERENCES}

1. Baseman, J. B., R. M. Cole, D. C. Krause, and D. K. Leith. 1982. Molecular basis for cytadsorption of Mycoplasma pneumoniae. J. Bacteriol. 151:1514-1522.

2. Baseman, J. B., D. L. Drouillard, D. K. Leith, and J. MorrisonPlummer. 1985. Role of Mycoplasma pneumoniae adhesin P1 and accessory proteins in cytadsorption, p. 18-23. In S. E. Mergenhagen and B. Rosan (ed.), Molecular basis of oral microbial adhesion. American Society for Microbiology, Washington, D.C.

3. Baseman, J. B., J. Morrison-Plummer, D. Drouillard, B. PuleoScheppke, V. V. Tryon, and S. C. Holt. 1987. Identification of a 32-kilodalton protein of Mycoplasma pneumoniae associated with hemadsorption. Isr. J. Med. Sci. 23:474-479.

4. Biberfeld, G., and P. Biberfeld. 1970. Ultrastructural features of Mycoplasma pneumoniae. J. Bacteriol. 102:855-861. 
5. Boyle, W. J., P. Van Der Geer, and T. Hunter. 1991. Phosphopeptide mapping and phosphoamino acid analysis by two-dimensional separation on thin-layer cellulose plates. Methods Enzymol. 201: 110-149.

6. Clyde, W. A., Jr. 1983. Mycoplasma pneumoniae respiratory disease symposium: summation and significance. Yale J. Biol. Med. 56: 523-527.

7. Collier, A. M., and W. A. Clyde, Jr. 1971. Relationships between Mycoplasma pneumoniae and human respiratory epithelium. Infect. Immun. 3:694-701.

8. Cooper, J. A. 1991. Estimation of phosphorylation stoichiometry by separation of phosphorylated isoforms. Methods Enzymol. 201:251-261.

9. Cozzone, A. J. 1988. Protein phosphorylation in prokaryotes. Annu. Rev. Microbiol. 42:97-125.

10. Denny, F. W., W. A. Clyde, Jr., and W. P. Glezen. 1971. Mycoplasma pneumoniae disease: clinical spectrum, pathophysiology, epidemiology, and control. J. Infect. Dis. 123:74-92.

11. Dirksen, L. B., H. Hilbert, T. Proft, R. Herrmann, and D. C. Krause. Unpublished data.

12. Edelman, A. M., D. K. Blumenthal, and E. G. Krebs. 1987. Protein serine/threonine kinases. Annu. Rev. Biochem. 56:567-613.

13. Foy, H. M., G. E. Kenny, M. K. Cooney, and I. D. Allan. 1979. Long-term epidemiology of infections with Mycoplasma pneumoniae. J. Infect. Dis. 139:681-687.

14. Göbel, U., V. Speth, and W. Bredt. 1981. Filamentous structures in adherent Mycoplasma pneumoniae cells treated with nonionic detergents. J. Cell Biol. 91:537-543.

15. Hahn, T., and D. C. Krause. Unpublished data.

16. Hancock, K., and V. C. W. Tsang. 1983. India ink staining of proteins on nitrocellulose paper. Anal. Biochem. 133:157-162.

17. Hansen, E. J., R. M. Wilson, and J. B. Baseman. 1979. Twodimensional gel electrophoretic comparison of proteins from virulent and avirulent strains of Mycoplasma pneumoniae. Infect. Immun. 24:468-475.

18. Hayflick, L. 1965. Tissue cultures and mycoplasmas. Tex. Rep. Biol. Med. 23(Suppl. 1):285-303.

19. Hu, P. C., A. M. Collier, and J. B. Baseman. 1977. Surface parasitism by Mycoplasma pneumoniae of respiratory epithelium. J. Exp. Med. 145:1328-1343.

20. Hunter, T., and J. A. Cooper. 1985. Protein-tyrosine kinases. Annu. Rev. Biochem. 54:897-930.

21. Kahane, I., J. Granek, and A. Reisch-Saada. 1984. The adhesins of Mycoplasma gallisepticum and M. pneumoniae. Ann. Microbiol. (Inst. Pasteur). 135A:25-32.

22. Kahane, I., S. Tucker, D. K. Leith, J. Morrison-Plummer, and J. B. Baseman. 1985. Detection of the major adhesin P1 in Triton shells of virulent Mycoplasma pneumoniae. Infect. Immun. 50:944 946.

23. Kemp, B. E., and R. B. Pearson. 1990. Protein kinase recognition sequence motifs. Trends Biochem. Sci. 15:342-346.

24. Kessler, S. W. 1976. Cell membrane antigen isolation with the staphylococcal protein A-antibody adsorbent. J. Immunol. 117: 1482-1490.

25. Krause, D. C., D. K. Leith, and J. B. Baseman. 1983. Reacquisition of specific proteins confers virulence in Mycoplasma pneumoniae. Infect. Immun. 39:830-836.

26. Krause, D. C., D. K. Leith, R. M. Wilson, and J. B. Baseman. 1982 Identification of Mycoplasma pneumoniae proteins associated with hemadsorption and virulence. Infect. Immun. 35:809-817.
27. Laemmli, U. K. 1970. Cleavage of structural proteins during the assembly of the head of bacteriophage T4. Nature (London) 227:680-685.

28. Leith, D. K., L. B. Trevino, J. G. Tully, L. B. Senterfit, and J. B. Baseman. 1983. Host discrimination of Mycoplasma pneumoniae proteinaceous immunogens. J. Exp. Med. 157:502-514.

29. Lipman, R. P., W. A. Clyde, Jr., and F. W. Denny. 1969. Characteristics of virulent, attenuated, and avirulent Mycoplasma pneumoniae strains. J. Bacteriol. 100:1037-1043.

30. Maurides, P. A., G. R. Akkaraju, and R. Jagus. 1989. Evaluation of protein phosphorylation state by a combination of vertical slab gel isoelectric focusing and immunoblotting. Anal. Biochem. 183:144 151.

31. Meng, K. E., and R. M. Pfister. 1980. Intracellular structures of Mycoplasma pneumoniae revealed after membrane removal. J. Bacteriol. 144:390-399.

32. Mobley, P. L., and B. C. Harrison. 1993. Cytoskeleton phosphorylation and cell morphology. Adv. Struct. Biol. 2:53-80.

33. Nairn, A. C. H. C. Hemmings, Jr., and P. Greengard. 1985 Protein kinases in the brain. Annu. Rev. Biochem. 54:931-976.

34. O'Farrell, P. H. 1975. High resolution two-dimensional electrophoresis of proteins. J. Biol. Chem. 250:4007-4021.

35. Platt, M. W., J. Reizer, and S. Rottem. 1990. A 57-kilodalton protein associated with Spiroplasma melliferum fibrils undergoes reversible phosphorylation. J. Bacteriol. 172:2808-2811.

36. Platt, M. W., and S. Rottem. 1988. Phosvitin kinase activity in Acholeplasma axanthum. FEBS Lett. 242:97-100.

37. Platt, M. W., S. Rottem, Y. Milner, M. F. Barile, A. Peterkofsky, and J. Reizer. 1988. Protein phosphorylation in Mycoplasma gallisepticum. Eur. J. Biochem. 176:61-67.

38. Reizer, J., M. J. Novotny, W. Hengstenberg, and M. H. Saier, Jr. 1984. Properties of ATP-dependent protein kinase from Streptococcus pyogenes that phosphorylates a seryl residue in HPr, a phosphocarrier protein of the phosphotransferase system. J. Bacteriol. 160:333-340.

39. Saier, M. H., Jr. 1993. Introduction: protein phosphorylation and signal transduction in bacteria. J. Cell. Biochem. 51:1-6.

40. Saier, M. H., Jr., L.-F. Wu, and J. Reizer. 1990. Regulation of bacterial physiological processes by three types of protein phosphorylating systems. Trends Biochem. Sci. 15:391-395.

41. Schüssler, P., and U. Göbel. 1990. Protein phosphorylation in Mycoplasma pneumoniae. IOM Lett. 1:300-301.

42. Sobeslavsky, O., B. Prescott, and R. M. Chanock. 1968. Adsorption of Mycoplasma pneumoniae to neuraminic acid receptors of various cells and possible role in virulence. J. Bacteriol. 96:695705.

43. Stevens, M. K., and D. C. Krause. 1990. Disulfide-linked protein associated with Mycoplasma pneumoniae cytadherence phase variation. Infect. Immun. 58:3430-3433.

44. Stevens, M. K., and D. C. Krause. 1991. Localization of the Mycoplasma pneumoniae cytadherence-accessory proteins HMW1 and HMW4 in the cytoskeletonlike Triton shell. J. Bacteriol. 173:1041-1050.

45. Stevens, M. K., and D. C. Krause. 1992. Mycoplasma pneumoniae cytadherence phase-variable protein HMW3 is a component of the attachment organelle. J. Bacteriol. 174:4265-4274.

46. Towbin, H., T. Staehelin, and J. Gordon. 1979. Electrophoretic transfer of proteins from polyacrylamide gels to nitrocellulose sheets: procedure and some applications. Proc. Natl. Acad. Sci. USA 76:4350-4354. 